\title{
Análise do tema bullying em revistas femininas para adolescentes
}

\author{
Ana Cláudia Bortolozzi Maia \\ Universidade Estadual Paulista (UNESP), Campus de Bauru e Araraquara, São Paulo-Brasil \\ aclaudia@fc.unesp.br \\ Marcela Pastana \\ Universidade Estadual Paulista (UNESP), Campus de Araraquara, São Paulo-Brasil \\ marcelapas@gmail.com
}

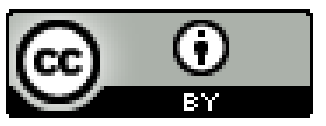

Educação: teoria e prática, Rio Claro, SP, Brasil - elSSN: 1981-8106

Está licenciada sob Licença Creative Common

\section{Resumo}

Práticas de violência como agressões físicas e verbais, provocações, humilhações e exclusões que ocorrem principalmente entre jovens nas escolas são chamadas de bullying e o objetivo deste estudo qualitativo-descritivo foi investigar como este fenômeno é representado pelas revistas direcionadas para garotas adolescentes. A análise foi realizada em 15 matérias de quatro revistas brasileiras: Capricho, Todateen, Atrevida e Yes Teen a partir de categorias temáticas: 1) Definições e explicações sobre o bullying; 2) Propostas das revistas para o enfrentamento do bullying (2.1 Campanhas e orientações contra o bullying, 2.2 Conselhos sobre como agir diante do bullying, 2.3 Exemplos de "superação" para quem sofreu bullying e 2.4. Conselhos dados a quem pratica o bullying). Foi identificada e discutida a presença de hierarquias, estereótipos e do incentivo à competição. Há a predominância de padrões normativos e excludentes, conselhos que individualizam a questão e ausência de reflexão crítica.

Palavras-chave: Bullying. Mídia. Adolescência.

\section{Analysis of the theme bullying in feminine magazines for teens}

\begin{abstract}
Practices of violence such as physical and verbal aggression, provocations, humiliations and exclusion that occur mainly among young people in schools are named as bullying and the aim of this qualitative-descriptive study was to investigate how this phenomenon is represented by magazines directed to teenage girls. The analysis was conducted in fifteen articles of four Brazilian magazines: Capricho, Todateen, Atrevida and Yes Teen through thematic categories: 1) Definitions and explanations about
\end{abstract}


bullying; 2) Magazines' proposals to the confrontation against bullying (2.1 Campaigns and orientations against bullying; 2.2 Advices about how to act in the presence of bullying; 2.3 Examples of "overcoming" to people who suffered bullying and 2.4 Advices given to people who practice bullying). It was identified the presence of hierarchies, stereotypes and the incentive to competition. There is the predominance of normative and excluding patterns, advices that individualize the issue and lack of critical reflection.

Keywords: Bullying. Media. Adolescente.

\section{Análisis del tema bullying en revistas femeninas para adolescentes}

\section{Resumen}

Prácticas de violencia como agresiones físicas y verbales, provocaciones, humillaciones y exclusiones que ocurren principalmente entre jóvenes en las escuelas son llamadas de bullying y el objeto de este estudio cualitativo-descriptivo fue investigar cómo este fenómeno es representado por las revistas dirigidas a las chicas adolescentes. El análisis se realizó en 15 materias de cuatro revistas brasileñas: Capricho, Todateen, Atrevida y Yes Teen a partir de categorías temáticas: 1) Definiciones y explicaciones sobre el bullying; 2 ) Propuestas de las revistas para el enfrentamiento del bullying $(2,1$ Campañas y orientaciones contra el bullying, 2.2 Consejos sobre cómo actuar frente al bullying, 2.3Ejemplos de "superación" para quien sufrió bullying y 2.4 Consejos dados a quien practica el bullying). Se identificó y discutió la presencia de jerarquías, estereotipos y del incentivo a la competición. Hay la predominancia de patrones normativos y excluyentes, consejos que individualizan la cuestión y la ausencia de reflexión crítica.

Palabras clave: Bullying. Mídia. Adolescencia.

\section{Introdução}

\subsection{Questões iniciais}

Em um projeto realizado em 2010, com 25 alunos de uma turma de nono ano do Ensino Fundamental de uma escola pública, quando discutimos sobre a passagem para o Ensino Médio, em que todos iriam para uma nova escola, um relato constante por parte dos alunos era sobre o medo de, ao chegar à nova instituição, não serem bem recebidos, não fazerem novos amigos e tornarem-se alvo de piadas, ridicularizações e rejeição. Realizamos, então, um encontro para discutirmos sobre o bullying, em que os alunos tiveram espaço para discutir sobre práticas de violência no ambiente da escola. A maior parte das falas não dizia respeito às experiências de bullying efetivamente sofridas, mas sim à ansiedade provocada pela possibilidade de que elas ocorressem, como no exemplo de uma aluna, que afirmou: "Antes de sair de casa para ir para a escola, olho no espelho várias vezes e imagino o que os outros 
poderão 'zoar' em mim naquele dia". Um dos meninos descreveu como agia para se defender: “Eu não espero que os outros me 'zoem', eu provoco primeiro, assim, enquanto todos estão prestando atenção em quem está sendo 'zoado', não vão olhar para mim para me 'zoarem' também". Embora as ações provocativas e depreciativas chamadas pelos alunos de "zoações" fossem frequentes nas interações do grupo, não havia uma ou mais práticas específicas a quem estas ações fossem dirigidas, mas aconteciam entre os alunos, no geral e, muitas vezes, justificadas como "brincadeiras". Por não haver ninguém que fosse foco da agressão, as "zoações" da sala não correspondem ao conceito de bullying, que, segundo Fante e Pedra "é caracterizado pela intencionalidade e continuidade das ações agressivas contra a mesma vítima, sem motivos evidentes, resultando em danos e sofrimento e dentro de uma relação desigual de poder, o que possibilita a vitimação." (2008, p. 33). Mesmo que as "zoações" que aconteciam no espaço da escola não correspondessem ao que é chamado de "bullying", essa era uma palavra muito utilizada pelos alunos, fonte tanto de interesse, quanto de preocupações. Era uma palavra também usada com frequência nos discursos midiáticos, como nas revistas femininas para adolescentes, que serão analisadas neste artigo.

\subsection{Questões teóricas}

Diante da crescente abordagem sobre o tema bullying na discussão sobre a violência nas escolas, entre jovens, familiares, professores, demais profissionais da educação e também nos meios de comunicação, nos pareceu relevante estudar como o tema é retratado nas revistas impressas, que atuam como pedagogias culturais de grande influência sobre os jovens leitores.

Concepções preconceituosas e práticas discriminatórias são presentes no cotidiano escolar, assim como na sociedade em geral. Como discutem Abramovay (2006), Facco (2009), Felipe e Bello (2009) e Ferrari (2010), já na educação infantil, é possível notar na interação entre as crianças a ocorrência de apelidos, piadas, provocações e ofensas que expressam como o aprendizado sobre as diferenças é, desde cedo, relacionado ao movimento de apontar e marcar pessoas que apresentem características que destoam dos padrões. Embora muitas vezes sejam naturalizadas, essas "pequenas" e repetitivas agressões cotidianas expressam a mesma lógica que culmina em situações que atualmente são nomeadas como bullying, em que a 
violência se dá de forma incisiva e contínua contra uma pessoa (FANTE, PEDRA, 2008).

Albino e Terêncio (2010) ressaltam a importância de se pensar os elementos que são considerados como característicos do bullying (exclusão, discriminação, humilhação e inferiorização) como aspectos presentes nas relações sociais como um todo. Antunes (2008) argumenta que a violência atualmente é naturalizada e banalizada e isso se reflete nas interações escolares. A autora problematiza como as pesquisas acadêmicas e as abordagens midiáticas sobre o bullying, muitas vezes, deixam de lado as influências sociais que o produzem, mediante explicações individualizantes, culpabilização dos sujeitos, delimitação de classificações binárias (bom x mau; vilão $x$ vítima), tipologias estereotipadas e a ênfase em aconselhamentos morais e medidas punitivas. A autora defende que, sem que haja a promoção de reflexão crítica sobre as contradições sociais e a busca por transformações, o foco incide apenas na adaptação individual, com o risco de que as relações desiguais sejam mantidas ao invés de combatidas.

Bezerra Júnior (1999), Costa (2004), Freire Filho (2011) e Kehl (2008) destacam que os modos de sociabilidade predominantes atualmente são marcados pela competitividade, por hierarquizações e exclusões, o que alimenta uma intolerância à alteridade. Há o temor constante, nas interações cotidianas, de ser julgado com sarcasmo, desprezo ou indiferença, sob a contínua ameaça de reprovação e rejeição. 0 outro é percebido com hostilidade e desconfiança, como um possível observador incômodo e invasivo dos desvios e das falhas do sujeito em corresponder aos padrões vigentes.

"Eles me chamam de feia, macaca, chata e gorda. Eu fico muito triste", foi uma frase dita por uma das participantes da pesquisa realizada por Anderson Ferrari (2010), com estudantes de uma escola pública de Ensino Fundamental em Minas Gerais, que deu nome ao artigo do autor que comenta que marcadores como classe, raça, gênero e padrões estéticos precisam ser considerados para compreendermos as práticas de agressividade e humilhação que ocorrem no espaço da escola. As diferenças são compreendidas como delimitadoras de grupos de pertencimento, com o estabelecimento de hierarquias entre aqueles que correspondem aos padrões, vistos como superiores, e aqueles que destoam deles, que se tornam alvo de inferiorizações, depreciações, ofensas e exclusões. Esse processo de hierarquização é intenso e participa na construção de subjetividades. Ferrari (2010) e Facco (2009) discutem 
como, muitas vezes, aqueles que são inferiorizados compartilham dos sentidos que estabelecem a exclusão e incorporam a noção de inadequação, por terem sido socializados na mesma lógica hierarquizante, que naturaliza a compreensão dos traços pelos quais são discriminados como indesejáveis, passíveis de reprovação e rejeição.

Os meios de comunicação, no geral, e as revistas, mais especificamente, participam no aprendizado sobre os padrões, sobre o que é tido socialmente como aceito e valorizado, e o que é tido como negativo e reprovável. A seguir, discutiremos sobre a presença e a transmissão desses padrões em revistas femininas para adolescentes.

Nas revistas há a predominância do discurso normativo permeado por regras e prescrições, sendo comuns matérias de aconselhamento apresentadas como "manuais" e "guias" sobre como as garotas devem ser, pensar e se comportar com ênfase na importância de agradarem e serem aceitas. Pesquisas realizadas sobre as revistas para adolescentes problematizam sobre como a elas se dirigem a um público específico, de forma a silenciar, omitir e excluir a diversidade e pluralidade de adolescências (FERREIRA; SILVA, 2007; FIGUEIRA, 2006; FISCHER, 1996; LIRA, 2009; MENDONÇA; RIBEIRO, 2009, 2008; MIGUEL, 2005; NIEMEYER; KRUSE, 2008; OLIVEIRA, 2009; SILVA, 2002).

Fischer (1996), ao analisar diferentes artefatos midiáticos voltados para adolescentes, dentre eles a revista Capricho, ressalta que o recorte de classe faz que muitos não sejam nem mesmo incluídos no termo "adolescentes" ou "teens", recebendo apenas a nomeação de "menores". Esses em nenhum momento são mencionados nas páginas das revistas, muito menos na publicidade, aparecendo apenas na condição de "outros", nas estatísticas oficiais, nas reportagens sobre problemas sociais, nas páginas policiais dos jornais.

Oliveira (2009) analisa o discurso sobre as adolescentes negras veiculados na revista Atrevida, e discute o quanto elas são representadas apenas por meio de aparições pontuais e deslocadas do conteúdo geral da revista, já que a interlocutora privilegiada é a adolescente branca. A autora ressalta o quanto a revista se pauta na manutenção do discurso hegemônico sobre beleza, gênero e raça, reiterando o lugar de cada grupo social na escala de valores predefinidas de acordo com os padrões vigentes.

Miguel (2005) analisou o discurso da revista Capricho em edições do período 
entre 1952 e 2003 e destacou o quanto na revista não são consideradas as diferenças culturais, sociais, de gênero, raciais, regionais, nacionais. Nesse período de 50 anos, encontrou matérias que abordaram a homossexualidade apenas 3 vezes e, nos conselhos dados, a atração por alguém do mesmo sexo era negada, colocada apenas como uma "fase", como uma admiração passageira. Ferreira e Silva (2007), ao analisarem as representações de sexualidade nas revistas Capricho, Todateen e Atrevida, entre 2003 e 2005, também discutem a ausência de temas como a homossexualidade, a transexualidade e a violência sexual.

Figueira (2002), Niemeyer e Kruse (2008) analisaram as representações de corpo veiculadas pela revista Capricho, destacando o quanto é ensinado que o sucesso e a realização dependem da construção de um corpo aceito e valorizado de acordo com os padrões estéticos vigentes, de modo que ser gorda e/ou feia é associado a irresponsabilidade, desleixo, descuido e falta de amor próprio.

Mesmo diante de tantas imagens padronizadas e estereotipadas sobre como deve ser a adolescência, as revistas se colocam na posição "didática" de ensinarem às jovens sobre como agir diante das dificuldades encontradas nas relações sociais (FISCHER, 1996; MIGUEL, 2005; NIEMEYER, KRUSE, 2008). Um exemplo é o caso de matérias e campanhas sobre o tema bullying, em que as garotas são aconselhadas e instruídas sobre como lidar com a questão.

A presença destas matérias e campanhas leva ao questionamento: Como as próprias revistas que, em suas páginas, apresentam um ideal de sucesso e perfeição atrelado à beleza, à magreza, à popularidade, à realização amorosa heterossexual, à riqueza, sendo praticamente inexistente a representação de adolescentes negras, pobres, gordas, homossexuais, que destoem do padrão de beleza vigente etc., almejam, diante da evidência do problema chamado de bullying, apresentar um discurso que valoriza o respeito à diversidade? As próprias revistas descrevem a exclusão como elemento característico nas ocorrências de bullying, o que torna importante considerar que a forma como as revistas são construídas pode contribuir para construir e fortalecer o quadro que elas declaram buscar combater.

O objetivo desta pesquisa qualitativa-descritiva é investigar como o tema bullying é abordado nas revistas femininas para o público adolescente. Almeja-se com os resultados contribuir para a reflexão sobre materiais que são amplamente utilizados por adolescentes e que contribuem nos processos educativos, como as revistas que 
são, muitas vezes, utilizadas acriticamente.

\section{Método}

Inicialmente foi realizado um levantamento com 100 adolescentes de uma escola pública de Ensino Fundamental da cidade de Bauru, sobre quais eram os materiais buscados por eles para obter informações. Os materiais mencionados com maior frequência foram as revistas e, dentre elas, as revistas femininas para adolescentes Capricho, Atrevida, Todateen e Yes Teen, que foram selecionadas para esta análise. A Tabela 1 mostra informações gerais sobre as revistas analisadas.

\begin{tabular}{l|l|l|l|l}
\hline \multicolumn{1}{c|}{ Revistas } & Capricho & Atrevida & Todateen & Yes Teen \\
\hline Ano de lançamento & 1952 & 1994 & 1995 & 2007 \\
\hline Editora & Abril & Escala & Alto Astral & On Line \\
\hline Periodicidade & Quinzenal & Mensal & Mensal & Mensal \\
\hline Tiragem & 194.915 & 146.000 & 85.000 & 200.000 \\
\hline
\end{tabular}

Tabela 1. Descrição geral das revistas analisadas.

Por meio da leitura das edições dessas revistas publicadas entre julho de 2010 e janeiro de 2011, foram identificadas as matérias que abordaram o tema bullying. Neste artigo, será apresentada a análise de 15 matérias: 10 da revista Capricho, 3 da revista Todateen, 1 da revista Atrevida e 1 da revista Yes Teen. Também foram analisadas as matérias publicadas no site da revista Capricho, em um blog criado especificamente para abordar a temática, "Diga Não ao Bullying", no período entre 8 de outubro e 23 de dezembro de 2010.

Diante das matérias selecionadas procedeu-se à análise de conteúdo, com base na proposta clássica de Bardin (1977), que propõe a explicitação, sistematização e expressão do conteúdo das mensagens analisadas. Assim, as etapas da análise temática consistiram nos seguintes passos: a) leitura flutuante das matérias selecionadas; b) exploração do material, assinalando as unidades de registro, isto é, recortes de conteúdos que expressem um tema gerador da categoria; c) tratamento dos resultados mediante a organização das categorias temáticas com inferência e interpretação. Os conteúdos organizados deram nome às categorias temáticas e 
subcategorias, mutuamente exclusivas, que foram discutidas com a literatura consultada, quais sejam: a) Definições e explicações sobre o bullying; b) Propostas das revistas para o enfrentamento do bullying (campanhas e orientações contra o bullying, conselhos sobre como agir diante do bullying, exemplos de "superação" para quem sofreu bullying e conselhos dados a quem pratica o bullying).

\section{Resultados}

\subsection{Definições e explicações sobre o bullying}

Nas matérias analisadas, foram apresentadas com frequência definições sobre o que é o bullying, acompanhadas de critérios de classificação para distinguir que práticas poderiam ser categorizadas ou não como "bullying", como no trecho a seguir, da matéria "Não sei se o que rola comigo é bullying":

\footnotetext{
Bullying é do mal

O bullying é uma zoação muito frequente que rola por muito tempo. Ele acontece do nada (não parte, por exemplo, de uma briga) e envolve um lado mais forte e um mais fraco, como um grupo de garotos que zoa uma garota só. (CAPRICHO, Edição 1110, p. 78).
}

Essa definição foi oferecida diante do relato de uma leitora sobre o incômodo que sentia com as piadas e provocações feitas pelos amigos da escola, que eram feitas em tom de brincadeira. A revista esclarece que não se trata de bullying, por acontecer entre amigo, e não entre "um lado mais forte e um mais fraco". O trecho a seguir refere-se à resposta dada a um depoimento de uma adolescente que, após ter brigado com um colega de sala, passou a ser alvo de humilhações e ofensas por parte dele. Como um dos critérios para a caracterização do bullying é que a violência aconteça sem motivo aparente, é esclarecido que essa situação não corresponde ao fenômeno:

Há uma linha tênue entre brincadeira de mau gosto e Bullying. Tenha em mente que Bullying é diferente de uma brincadeira inconsequente: ele se dá sem motivo, de forma repetitiva e contra o mesmo alvo. É uma violência gratuita por dias, meses, anos. Além disso, há um desequilíbrio de forças entre a vítima e o agressor. No seu caso, houve um desentendimento entre vocês dois - você brigou feio com o garoto. (Blog Diga Não ao Bullying- Site da CAPRICHO). 
O fato de ter havido um desentendimento anterior faz com que a situação não seja classificada como bullying. As agressões praticadas pelo colega de sala são colocadas como uma "brincadeira de mau gosto" e "brincadeira inconsequente", o que aponta como, ao se prender em classificações que dividem ações "bullying/ não bullying", a revista pode, ao invés de esclarecer e problematizar as situações de violência, amenizá-las como "brincadeiras". Se a agressão não for repetitiva, com a intenção de causar dano e sem motivo, não é categorizada como bullying e, por isso, deixa de ser foco das discussões realizadas sobre o tema. Essa forma de lidar com a questão reforça o argumento de Antunes (2008) de que muitos discursos priorizam apenas conceituar o bullying e não discutem seu significado social. As descrições muitas vezes apresentam um caráter universalizante e estático, o que negligencia os aspectos dinâmicos e específicos de cada ocorrência, além de invisibilizar o impacto de fatores históricos e sociais. A autora problematiza como o próprio critério "sem motivo" pode dificultar uma compreensão mais ampla e contextualizada do bullying enquanto manifestação de violência.

Em ambos os exemplos estão presentes definições sobre o bullying: "bullying é do mal", envolve "um lado mais forte e um mais fraco", com "um desequilíbrio de forças entre vítima e agressor". Bem x mal, forte $x$ fraco, vítima $x$ agressor: as definições dadas envolvem a utilização de binarismos que simplificam as relações em que a violência ocorre.

Albino e Terêncio (2010), Antunes (2008) e Ferrari (2010) discutem como é contraditório que justamente o movimento de rotular e estereotipar, que ocorre nas práticas chamadas de bullying, seja repetido na busca para compreendê-lo. Desse modo, os estereótipos são presentes nas provocações, ofensas, piadas e humilhações e também nas explicações sobre elas. A presença de tipologias estereotipadas pode ser notada nos exemplos a seguir:

Bullying de menino: eles são mais explícitos e podem até partir para a agressão física. Bullying de menina: elas preferem espalhar fofocas do mal e isolar a vítima da turma. (TODATEEN, Edição 175, p. 73)

Quem costuma praticar o bullying não tem critério para escolher suas vítimas. 
Também é comum que essa "galera do mal" sempre procure pessoas que não se encaixam no grupo deles: o nerd da sala, a garota que não está em nenhuma panelinha pop, o menino que é magrinho, portanto mais fraco (fisicamente, claro), do que eles etc. (YES! TEEN, Edição 34, p. 33).

Exemplificar o bullying com base na divisão binária entre os gêneros, como "bullying de menina" e "bullying e menino", com a atribuição de características padronizadas sobre como meninos e meninas agem, é um exemplo de como, ao invés de esclarecer, as informações transmitidas podem contribuir para reforçar modos de ver o mundo baseados em estereótipos. "Galera do mal", "nerd", "panelinha pop" são, também, exemplos de como os estereótipos e rótulos estão presentes nas matérias sobre o bullying, lembrando os argumentos de Antunes (2008) e Ferrari (2010) de que partir de um discurso hierarquizante para explicar as agressões é um modo de reforçar o problema.

Ferrar (2010) afirma ser um equívoco pensar que as relações chamadas de bullying se dão apenas entre o par agressor-vítima, já que aqueles que presenciam e assistem ao bullying são indispensáveis para o reconhecimento e a legitimação da hierarquia construída. Ou seja, a atuação pontual diante de situações específicas é insuficiente, considerando que a lógica da disputa, da competitividade, da hierarquização não está presente apenas no contexto do bullying, mas nas relações como um todo.

\subsection{Propostas das Revistas para o enfrentamento do bullying}

\subsubsection{Campanhas e orientações contra o bullying}

Nas matérias sobre o tema bullying, as revistas trazem explicações, orientações e conselhos para as leitoras sobre como lidar com o assunto. Esse movimento pode ser ilustrado pela iniciativa da revista Capricho, que, no ano de 2010, lançou a campanha "Diga Não ao Bullying", que deu origem a uma nova seção na revista e propostas de discussão sobre o tema em um blog na internet e em palestras em escolas. Exemplos de trechos sobre o que motivou a iniciativa:

Nem sempre levar o caso de bullying para a diretoria é a melhor forma de combatê-lo. Muitos colégios não estão preparados para lidar com o problema e 
podem se atrapalhar e expor ainda mais quem sofre as agressões. (CAPRICHO, 1108, p. 78).

Talvez a parte mais difícil de tudo isso seja encontrar a melhor solução. Rolam as dúvidas: e se eu contar para o diretor e o pessoal da classe ficar sabendo? Vão me zoar mais ainda. E se eu contar para a minha mãe e ela achar que é frescura, dizer pra eu não ligar?(...) E é por isso que a CAPRICHO entende que precisa ajudar você a achar a tal solução. E vamos fazer isso com uma grande campanha. (CAPRICHO, Edição 1107, p. 6).

É possível notar a ênfase na compreensão de que diretores, professores e familiares não estão preparados para lidar com o assunto. Embora combater o bullying seja descrito como dever da escola, é afirmado que determinadas medidas podem atrapalhar e agravar o sofrimento. Diante desse quadro, a revista assume o papel educativo e se coloca na posição de ser a melhor instância para ajudar, orientar e aconselhar sobre o problema, lembrando o que discute Fischer (1996) sobre como os espaços midiáticos assumem um caráter pedagógico, apresentando-se como capazes de ensinar as pessoas, principalmente os adolescentes, sobre como ser e agir. Para esta autora, no entanto, essa postura didática não se pauta na promoção da reflexão, do pensamento crítico e de uma leitura aprofundada sobre o contexto social, histórico e político, mas sim no oferecimento de uma série de prescrições a serem seguidas e de conselhos sobre como buscar o modo de vida ideal.

Além da campanha, a linguagem didática também está presente em outras matérias da Capricho e das demais revistas: "Faça o Final Feliz" (CAPRICHO, Edição 1104), "Diga Não ao Bullying" (CAPRICHO, Edição 1107), "Lições de quem sofreu bullying (CAPRICHO, Edição 1114), "10 dicas contra o bullying" (TODATEEN, Edição 182), "Chega de bullying!" (YES TEEN, Edição 34). A utilização do modo imperativo e de termos como "lições" e "dicas" ilustra como é predominante o caráter prescritivo.

\subsubsection{Conselhos sobre como agir diante do bullying}

Os conselhos oferecidos sobre como lidar com o bullying não envolvem a compreensão critica e a reflexão necessária para uma possível transformação do contexto mais amplo, mas apresentam o problema de forma individualizada. O foco é, 
sobretudo, no incentivo de que a adolescente seja capaz de enfrentar a violência por meio de ações pessoais e mudanças autocentradas:

Dê end no bullying - Você terá vontade de se isolar de todos mas tente resistir: continuar agindo normalmente é um jeito de mostrar força, pois os autores do bullying querem mesmo que você se sinta diminuída. (CAPRICHO, Edição 1112, p. 81)

Tenha autoestima: Assim, você cria coragem para intervir pelos outros e não ser uma vítima do bullying. Aumentar a confiança em si mesma é um ótimo exercício diário, e ajudar os outros pode ser um bom começo. (TODATEEN, Edição 182, p. 76).

Não gosto de clichê mas é verdade: a mudança começa com a gente mesmo. Diga a você, todo dia, que é linda. Claro: acreditar nisso leva um tempo. Sempre tem alguém querendo te derrubar, mas é preciso levantar sempre! Eu ainda caio, mas continuo lutando e estou bem melhor do que já estive. Lorena, 16 anos. (CAPRICHO, Edição 1114, p. 79).

Em uma folha de papel, anote todas as zoações que te fazem e, em seguida, escreva que tipo de reação poderia ser adequada de sua parte. Pense no que poderia fazer para pararem de te incomodar. Isso vai te deixar mais preparada da próxima vez que te pegarem pra encher. Depois de escrever tudo, rasgue o papel em pedacinhos, como se essas agressões fizessem parte do passado. Se possível, fique zen e não deixe o intimidador perceber que você está incomodado. Porque esse é o motivo do bullying: te perturbar. Deixe um objeto no seu bolso - como um amuleto da sorte - para que você possa segurar quando sentir raiva ou medo. (Blog Diga Não ao Bullying- Site da CAPRICHO).

As ações sugeridas de enfrentamento ao bullying nas revistas são concentradas no campo da individualidade: agir normalmente, mostrar força, aumentar a confiança em si mesma, começar a mudança por si mesma, dizer a si mesma que é linda todos os dias, levantar sempre, ficar zen, carregar um amuleto, escrever numa folha de papel as provocações recebidas e rasga-la. Para Freire Filho (2011), as soluções autocentradas, como a valorização da autoestima, têm sido cada vez mais recomendadas pelos 
discursos midiáticos como solução para os mais diversos problemas, como ter saúde, bem-estar, qualidade de vida e sucesso financeiro, profissional, amoroso e social. Para esse autor, as receitas colaboram para que a compreensão e a reflexão crítica sobre o contexto social sejam vistos como dispensáveis, já que o que importa são as capacidades e motivações individuais. Ainda que passem por dificuldades, não cabe aos indivíduos se mobilizarem em busca por transformação das condições em que vivem, mas sim investirem esforços para potencializar a "força interior" e se adequarem às situações adversas.

\subsubsection{Exemplos de "superação" para quem sofreu bullying}

Com a proposta de ajudar as adolescentes a lidarem com o bullying, além de conselhos, as revistas trazem depoimentos de outras garotas e, principalmente, de pessoas famosas, sobre terem passado pela mesma situação e terem conseguido superá-la.

Sim, até ela! A diva Miley sofreu bullying no colégio quando ela tinha tinha 10 anos. "Eu era solitária, sem amigos e muito triste", conta. (...) Miley sofreu muito na mão de um grupo de garotas, os "integrantes" do "Clube Anti-Miley". (...)

Quem ri por último... Só que, como todas as fãs de Miley sabem, a garota sem amigos riu por último. A vida dela mudou instantaneamente assim que se tornou a protagonista do seriado Hannah Montana, da Disney. (Blog Diga Não ao Bullying- Site CAPRICHO).

O vocalista da banda Coldplay tem uma história curiosa sobre bullying. Ele era atormentado por um valentão do colégio porque preferia tocar violão e piano em vez de praticar esportes. Certo dia, Chris Martin estava andando com sua esposa, a atriz Gwyneth Paltrow, e encontrou o tal do bullie. "Ele sempre me dizia que eu não seria nada na vida", Chris comenta. Com uma pontinha de sentimento de vingança, o cantor de "Clocks" perguntou para o ex-colega o que ele estava fazendo da vida. "Me senti muito bem perguntando isso." Ele não fazia nada de mais. Aí me virei e disse: "Essa é minha esposa, Gwyneth". Ele ficou com o rosto corado e estava muito envergonhado. (Blog Diga Não ao Bullying- Site CAPRICHO).

Sofri muito por causa do bullying. Mas quando fiz novas amizades, descobri 
minhas qualidades. (...) Passei a observar as pessoas que me faziam sofrer, e, sem ser metida nem nada, percebi que era muito melhor que elas! Bianca, 14 anos. (CAPRICHO, Edição 1114, p. 79).

No primeiro exemplo é apontado que a atriz "riu por último"; no segundo, é relatado sobre como o cantor se sentiu bem ao envergonhar o ex-colega porque agora ele é famoso enquanto o outro não faz "nada demais"; e, no último, a leitora superou o sofrimento percebendo ser "muito melhor". É possível notar como, nos exemplos de superação, a hierarquização entre pessoas melhores e piores, felizes e infelizes, bemsucedidas e fracassadas se mantém e é valorizada. Kehl (2008) discute como, nos discursos midiáticos, a possibilidade de se destacar, de receber reconhecimento, valorização e admiração é, muitas vezes, vinculada à possibilidade de despertar inveja, em ser visto como melhor, como superior aos outros, com a constante incitação da rivalidade e da competição.

Os ídolos, os mesmos que aparecem com frequência nas páginas das revistas para exibir o ideal de felicidade ligado à beleza, à riqueza, ao status, ao sucesso, elementos que fomentam a competição e a exclusão (FISCHER, 1996; FREIRE FILHO, 2011; KEHL, 2008; LIRA, 2009), são posicionados como referência nos discursos contra o bullying, convidados, nas palavras de Freire Filho (2011), a descreverem as "narrativas da vida vitoriosa" (p. 731).

Nos exemplos analisados, a solução apresentada para aqueles que sofrem bullying não é a da busca por relações menos violentas, menos pautadas na comparação e na inferiorização. Ao invés do questionamento de padrões que fomentam a hierarquização, há o estímulo à competitividade e à disputa, à possibilidade de, um dia, a leitora despertar inveja e humilhar aqueles que a fizeram se sentir humilhada. A apresentação de relatos de famosos que sofreram bullying antes de se tornarem celebridades é feita com o objetivo de incentivar o "otimismo", já que a "vingança" poderá ser muito prazerosa no futuro.

\subsubsection{Conselhos dados a quem pratica o bullying}

Nos conselhos dados para quem pratica o bullying, há a presença do tom de ameaça e acusação:

A coisa está tão séria que hoje existem medidas legais (isto é, de acordo com a lei) 
que punem, sim, quem pratica o bullying ou o cyberbullying. Então, antes de tentar ser engraçadinha ou colaborar com o grupo dos "malandrinhos" do colégio, vale pensar duas vezes antes de fazer uma brincadeirinha, afinal, a coisa pode ficar feia pro seu lado. (YES TEEN, Edição 34, p. 33).

Você já praticou o bullying? O que era brincadeira de mau gosto no passado, hoje é coisa séria, e disso você já sabe, não é? A piadinha com o nome da amiga, a zoação com o nerd da classe ou a treta que termina em tapas sem beijos são consideradas atitudes criminosas, que podem levar o agressor para a cadeia ou resultar em uma multa de 3 a 20 salários mínimos! \#caro (...) Decida de que lado ficar! (ATREVIDA, Edição 195, p. 102).

Aqui é possível notar a contradição: busca-se combater práticas agressivas com um tom também agressivo. Assim como nos conselhos para aquelas que sofrem o bullying, nos conselhos para quem o pratica também não há o incentivo à discussão e à reflexão. Antunes (2008) questiona intervenções que se baseiem na punição, no aconselhamento moral e em apelos para que os alunos ajam de forma "pacífica", no lugar de problematizações e discussões críticas efetivas sobre os múltiplos fatores envolvidos nos contextos de violência. Felipe e Bello (2009), Facco (2009) e Ferrari (2010) discutem como o incentivo à tolerância entre os diferentes não é suficiente, sem que seja considerado como se dá a construção das diferenças, como as classificações e hierarquizações são produzidas e reproduzidas.

\section{Considerações finais}

A partir das matérias das revistas femininas analisadas, Capricho, Todateen, Atrevida e Yes Teen, é possível identificar que, apesar da proposta de abordar o tema bullying de forma "didática", o que predomina são explicações que simplificam e reduzem a questão da violência a classificações estereotipadas e aconselhamentos focados no nível individual e não em uma contextualização mais ampla e na reflexão crítica sobre os fatores sociais envolvidos. Assim, embora se apresentem como capazes de auxiliar as leitoras a agirem diante do bullying, este auxílio se dá de forma prescritiva e normativa, sem que os padrões excludentes sejam problematizados e questionados.

A utilização de binarismos para descrever as relações, com pares como "bom e 
mau", "vilão e vítima" e "forte e fraco", assim como o incentivo à competição e o reforço de hierarquias presentes nos modelos de superação mostram como é contraditório que a busca por combater e solucionar o bullying seja realizada com os mesmos termos que caracterizam o problema.

Como apontam as pesquisas sobre as revistas mencionadas na introdução, as representações trazidas pelas revistas envolvem a exclusão da pluralidade de adolescências, com um modo homogêneo e padronizado de representar o gênero, a orientação sexual, a classe sexual, a raça, o corpo, de forma que garotas pobres, negras, homossexuais, obesas, entre tantas outras que constituem grupos marginalizados e tantas vezes alvos de discriminação e violência, são também silenciadas e negadas pelos discursos midiáticos.

A discussão mais ampla sobre o bullying envolveria a problematização e o questionamento da lógica de exclusão que embasa a construção das próprias revistas. Descrições simplistas e pontuais, receitas sobre como lidar que individualizem tanto o problema como as possíveis soluções, divisões entre melhores e piores e modelos idealizados sobre como as adolescentes podem se tornar no futuro são alguns dos elementos que contribuem para que a lógica que hierarquiza e exclui continue intacta. A análise corrobora outros estudos e coloca em evidência a necessidade de se pensar criticamente sobre as revistas que são amplamente utilizadas pelo público jovem.

\section{Referências}

ABRAMOVAY, M. Cotidiano das escolas: entre violências. Brasília: UNESCO, 2006. 389 p.

ALBINO, P. L.; TERÊNCIO, M. G. Considerações críticas sobre o fenômeno do Bullying: do conceito ao combate e a prevenção. Florianópolis: Prefeitura Municipal de Florianópolis, 2010. Disponível em <http://portal.pmf.sc.gov.br/index.php>Acesso em: 18 mar. 2010.

ANTUNES, D. C. Razão instrumental e preconceito: reflexões sobre o bullying. 2008. 230f. Dissertação (Mestrado em Educação) - Centro de Educação e Ciências Humanas, Universidade Federal de São Carlos, São Carlos, 2008.

BARDIN, L. Análise de conteúdo. Lisboa: Edições 70, 1977. 225p.

BEZERRA JUNIOR, B. C. Solidariedade contra a violência.Cadernos Juventude Saúde e Desenvolvimento, Brasília, v. 1, 1999. Disponível em 
<http://www.bvsde.paho.org/bvsacd/cd26/fulltexts/0399.pdf> Acesso em: 30 mar. 2010.

COSTA, J. F. O vestígio e a aura: corpo e consumismo na moral do espetáculo. Rio de Janeiro: Garamond, 2004. 242 p.

FACCO, L. Era uma vez um casal diferente: a temática homossexual na educação literária infanto-juvenil. São Paulo: Summus, 2009. 296p.

FANTE, C.; PEDRA, J. A. Bullying escolar: perguntas e respostas. Porto Alegre: Artmed, 2008. $105 \mathrm{p}$.

FELIPE, J.; BELLO, A. T. Construção de comportamentos homofóbicos no cotidiano da educação Infantil. In: JUNQUEIRA, R. D. (Org.). Diversidade sexual na educação: problematizações sobre a homofobia nas escolas. Brasília, Ministério da Educação, Secretaria de Educação Continuada, Alfabetização e Diversidade, Unesco, 2009. p. 141157. (Coleção Educação Para todos, vol. 32).

FERRARI, A. "Eles me chamam de feia, macaca, chata e gorda. Eu fico muito triste": classe, raça e gênero em narrativas de violência na escola. Instrumento: Revista Est. Pesq. Educ. Juiz de Fora, v. 12, n. 1, p. 21-30, 2010.

FERREIRA, G. M. ; SILVA, P. C. . A sexualidade construída nas páginas das revistas adolescentes: um estudo de caso de Atrevida, Capricho e TodaTeen. In: GIOVANDRO, M. F.; DALMONTE, E. F. (Org.). Comunicação e pesquisa: região, mercado e sociedade digital. Salvador: EDUFBA/Editora da Universidade Federal da Bahia, 2007. p. 79-94.

FIGUEIRA, M. L. M. Representações de corpo adolescente feminino na revista Capricho: saúde, beleza e moda. 2002. 171 f. Dissertação (Mestrado em Ciências do Movimento Humano) - Escola de Educação Física, Universidade Federal do Rio Grande do Sul, Porto Alegre, 2002.

FISCHER, R. M. B. Adolescência em discurso: mídia e produção de subjetividade. 1996. 297 f. Tese (Doutorado em Educação), Universidade Federal do Rio Grande do Sul, Porto Alegre, 1996.

FREIRE FILHO, J. O poder em si mesmo: jornalismo de autoajuda e a construção da autoestima. Revista FAMECOS (Impresso), v. 18, p. 717-745, 2011.

KEHL, M. R. A fratria órfã: conversas sobre a juventude. São Paulo: Olho d'água, 2008. 216p.

LIRA, L. C. E. Como se constrói uma mulher: uma análise do discurso nas revistas brasileiras para adolescentes. 2009. 179 f. Dissertação (Mestrado em Linguística) Universidade de Brasília, Brasília, 2009.

MENDONÇA, J. G.; RIBEIRO, P. R. M. O universo feminino como centro de interesse e de estudo em dissertações de mestrado: anotações de uma pesquisa bibliográfica.

Revista Ibero-Americana de Estudos em Educação, Araraquara, v. 4, n.2, 2009. 
O universo feminino como centro de interesse e de estudo em teses de doutorado: notas para a reflexão a partir de uma pesquisa bibliográfica. Revista IberoAmericana de Estudos em Educação, Araraquara, v. 3, n.1 e 2, 2008.

MIGUEL, R. B. P. De "moça prendada à "menina super poderosa": um estudo sobre as concepções de adolescência, sexualidade e gênero na revista Capricho (1952-2003). 2005. 169 f. Dissertação (Mestrado em Psicologia) - Centro de Filosofia e Ciências Humanas, Universidade Federal de Santa Catarina, Florianópolis, 2005.

NIEMEYER, F.; KRUSE, M. H. L. Constituindo sujeitos anoréxicos: discursos da revista Capricho. Texto contexto: enfermagem, Florianópolis, v. 17, n. 3, p. 457-465, 2008.

OLIVEIRA, C. S. As adolescentes negras no discurso da revista Atrevida. 2009. $154 \mathrm{f}$. Dissertação (Mestrado em Educação) - Curso de Mestrado da Faculdade de Educação, Universidade Federal de Minas Gerais, Belo Horizonte, 2009.

\section{Sites Consultados}

http://atrevida.uol.com.br/ http://capricho.abril.com.br/ http://todateen.uol.com.br/ http://www.yesteen.com.br/

\section{Revistas analisadas}

ATREVIDA, São Paulo: Editora Escala, nov. 2010, n. 195. CAPRICHO, São Paulo: Editora Abril, ago. 2010, n. 1004. CAPRICHO, São Paulo: Editora Abril, out. 2010, n. 1107. CAPRICHO, São Paulo: Editora Abril, nov. 2010, n. 1109. CAPRICHO, São Paulo: Editora Abril, nov. 2010, n. 1110. CAPRICHO, São Paulo: Editora Abril, dez. 2010, n. 1111 CAPRICHO, São Paulo: Editora Abril, dez. 2010, n. 1112. CAPRICHO, São Paulo: Editora Abril, jan. 2011, n. 1114. TODATEEN, Bauru: Editora Alto Astral, jun. 2010, n. 175. TODATEEN, Bauru: Editora Alto Astral, jan. 2011, n. 182. YES TEEN, São Paulo: On Line, out. 2010, n. 34. 